Copyright (c) 2022 Paranoá

(c) (i)

Este trabalho está licenciado sob uma licença Creative Commons Attribution 4.0 International License. Fonte:

https://periodicos.unb.br/index.php/paranoa/article/view/10902. Acesso em: 19 jan. 2022.

Referência

LEMOS, Natália da Silva; ANDRADE, Liza Maria da Souza de. de; MEDEIROS, Valério Augusto Soares de. Desafios do planejamento urbano no Brasil e seus marcos legais sob a ótica da agricultura urbana. Paranoá, Brasília, v. 14, n. 14, 2015. DOI:

10.18830/issn.1679-0944.n14.2015.16988. Disponível em:

https://periodicos.unb.br/index.php/paranoa/article/view/10902. Acesso em: 19 jan. 2022. 


\title{
Desafios do Planejamento Urbano no Brasil e seus Marcos Legais sob a Ótica da Agricultura Urbana
}

\author{
LEMOS, Natália da Silva ${ }^{1}$ \\ ANDRADE, Liza Maria da Souza de ${ }^{2}$ \\ MEDEIROS, Valério Augusto Soares de ${ }^{3}$ \\ ${ }^{1}$ Universidade de Brasília, Brasília, Brasil. lemos.natalia@gmail.com \\ ${ }^{2}$ Universidade de Brasília, Brasília, Brasil. lizamsa@gmail.com \\ ${ }^{3}$ Universidade de Brasília, Câmara dos Deputados, UNIEURO, Brasília, Brasil. vaugusto@unb.br
}

\section{Resumo}

Diante de um futuro incerto de mudanças climáticas, prevê-se um colapso em grandes cidades do mundo. O cenário é produto da insegurança alimentar gerada pelo distanciamento da agricultura local das áreas adjacentes ao espaço urbano, contexto já identificado em algumas civilizações no passado. Sob a perspectiva, assume-se que ações de planejamento urbano devem estar integradas a estratégias de produção de alimentos a incluir iniciativas em favor da agricultura urbana e periurbana, e de práticas da permacultura. A considerar tais premissas, o objetivo da pesquisa é demonstrar os desafios do planejamento urbano no Brasil quando analisado sob a ótica da agricultura urbana. Entende-se a necessidade de assumir novos conceitos e modelos de composição do espaço, associados à permacultura e sua prática experimental, considerando a integração dos contextos urbanos (zonas intraurbanas, periurbanas e rurais) que atualmente não apresentam claras inter-relações. Para aproximar o estudo à realidade brasileira foram analisadas, conjuntamente, as políticas sociais do Ministério do Desenvolvimento Social e os marcos legais das políticas urbanas, a incluir o Estatuto da Cidade (Lei 10.257/2001) e a Lei 6.766/1979. Os resultados apontam que há uma lacuna quanto às ações e práticas de agricultura urbana no âmbito legal de uso e ocupação do solo e, portanto, sugerem-se algumas diretrizes de aplicação.

Palavras-Chave: Agricultura urbana, planejamento urbano, sustentabilidade urbana, zonas territoriais e uso do solo.

\begin{abstract}
The climate change process is providing an uncertain future, supporting the forecast of big cities collapse. The scenery is product of the food insecurity issue generated by the distance between the local farmers and the urban surrounding areas, a situation already reported in civilizations in the past. Considering this perspective, it is assumed that urban planning actions must be integrated to food production strategies such as urban and peri-urban agriculture and permaculture practices. Based on these premises, this paper aims at demonstrating the challenges of the urban planning in Brazil when analyzed under the urban agriculture point of view. It is clear the necessity of assuming new concepts and models to organize urban spaces, associated with permaculture and its experimental practice, considering the integration of urban contexts (intraurban, peri-urban and rural zones) that nowadays are not properly related. In order to develop a Brazilian approach, the social policies of the Ministry of Social Development and the urban policies legal framework - the Estatuto da Cidade (Law 10.257/2001) and Law 6.766/1979 were analyzed. The results point that there is a gap regarding the urban agriculture actions and practices in the legal context related to land use. Therefore, guidelines are suggested to deal with the explored issue.
\end{abstract}

Key-Words: Urban agriculture, urban planning, urban sustainability, territorial sections and land use sections. 


\section{Introdução}

Dentre as muitas razões para o declínio das cidades, Moore (2006) afirma que a mais importante é o colapso da agricultura local, como pôde ser visto nas civilizações asiáticas e maias. As cidades são dependentes e sustentadas pela agricultura de seus arredores, o que significa que qualquer perturbação no ciclo produtivo pode levar à morte do assentamento, de sua população, comércio e riqueza.

A atividade agropecuária, tradicionalmente envolvendo grande número de pessoas na produção de alimentos, é frágil em face de uma possível crise do petróleo. O contexto torna a prática, sob o atual modelo existente, inviável: nela reside uma intensa confiabilidade nos combustíveis fósseis para a produção e o transporte alimentar.

Em tempos de crise econômica, os níveis de subsistência alimentar resultam diretamente de acesso aos alimentos, o que expressa a importância da economia rural e da agricultura urbana. A Fundação da Organização das Nações Unidas para Agricultura e Alimentação (FAO/ONU) revela que vários países passam por problemas de segurança alimentar como uma consequência direta dos conflitos recentes, crises de longo prazo, da insuficiência dos meios de produção e subsistência, das catástrofes naturais e da capacidade de gestão.

A prática da agricultura urbana tem sido, portanto, uma vantagem em tempos de crise, apontar cenários alternativos para a melhoria das situações locais. Hoje em dia, os métodos utilizados para incentivar atividades agrícolas nas cidades derivam das práticas desenvolvidas durante os anos 60 e 70 nos Estados Unidos, período em que a agricultura urbana evoluiu e derivou para o seu foco na preservação do meio ambiente, justiça social e desenvolvimento econômico.

Atualmente, cresce o número de práticas de agricultura urbana em todo o mundo, inclusive na América Latina. A meta principal é reduzir as desigualdades sociais, tendo em vista que $50 \%$ dos gastos de uma família são com alimentação. Alguns exemplos são registrados em Belo Horizonte (Figura 1), Bogotá, Cidade do México, Lima, Santiago e outras (ONU/FAO, 2014).
Figura 1: Horta comunitária Vila Pinho, em Belo Horizonte.

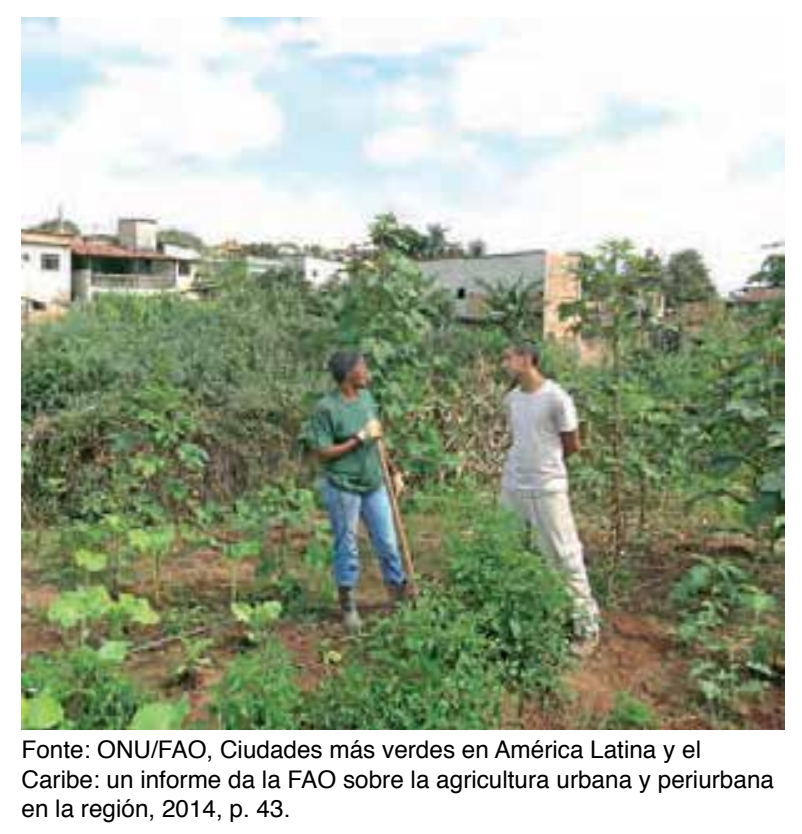

A agricultura urbana, como um elemento de planejamento urbano, visa promover a integração da prática com a vida urbana. Há destaque para os benefícios da gestão ambiental e da sustentabilidade, como consequência do desenvolvimento de um zoneamento coerente com as suas definições espaciais resultantes dos atributos locais na cidade.

A considerar tais premissas, o objetivo do estudo ${ }^{1}$ é demonstrar os desafios do planejamento urbano no Brasil quando analisado sob a ótica da agricultura urbana. Entende-se a necessidade de inserir novos conceitos e modelos de composição do espaço tendo em conta a permacultura e sua prática experimental, considerando a integração dos contextos urbanos (zonas intraurbanas, periurbanas e rurais) que não apresentam claras inter-relações contemporaneamente.

Para o alcance dos resultados, no primeiro momento foi desenvolvido um estudo sobre os contextos e os benefícios da agricultura urbana para o ambiente da cidade. Foram avaliados a prática e o modelo espacial presentes na permacultura, focando principalmente o zoneamento espacial e produtivo. De acordo com Mollison e Slay (1998), a permacultura consiste em uma estratégia de design que abrange iniciativas e arranjos naturais de um determinado lugar e seus arredores, tendo como

1 O estudo é resultante da Monografia de Natália da Silva Lemos desenvolvida no curso de especialização Reabilita, da Faculdade de Arquitetura e Urbanismo na Universidade de Brasília. Este artigo é uma tradução adaptada e revisada do texto Urban planning through the prism of urban agriculture, apresentado na International Conference on Changing Cities: spatial, morphological, formal \& socioeconomic dimensions. Skiathos island, Greece: 2013 
prioridade o conceito de múltiplas funções para cada espaço.

Em seguida, com base nas premissas dos documentos "Panorama da agricultura urbana e periurbana no Brasil e diretrizes políticas para sua promoção" (BRASIL, 2007), "Agricultura urbana" (EMBRAPA, 2002), e discussões de Mougeot (2000), foi realizada uma análise do contexto da agricultura urbana em face do zoneamento urbano, a fim de entender como a associação entre ambos a partir da maneira como as pessoas experimentam a vida urbana. O objetivo da sessão foi compreender os benefícios e o modo como a agricultura urbana pode ter lugar dentro da cidade e qual a estrutura seria necessária em termos de zoneamento, para conformar uma atividade estruturalmente convergente.

Estudos baseados em Brasil (2007) e Mougeot (2005) identificaram falhas quanto à incorporação de ações voltadas para a prática da agricultura urbana nos instrumentos de políticas urbanas desenvolvidos no Estatuto da Cidade. Com base em Mollison e Slay (1998) e Mougeot (2000), foi produzido um agrupamento entre o zoneamento permacultural e a agricultura urbana, a fim de gerar um uso da terra que englobasse ambos, subdividindo-se em três zonas macro: urbana, periurbana e rural.

Em resposta aos desafios apontados nos documentos investigados e Mougeot (2005), foi desenvolvido um estudo sobre a agricultura urbana como atividade legal em face às políticas urbanas brasileiras e seus marcos legais, a Lei 10.257/2001 (Estatuto da Cidade) e a Lei 6.766/1979. Posteriormente, a partir dos resultados obtidos, apresenta-se uma sugestão de aplicação de diretrizes para inclusão da agricultura urbana.

Cabe o esclarecimento que a Lei 6.766/1979, utilizada como base para o estudo, passará por processo de ajuste pelo Projeto de Lei $n^{\circ} 3.057 / 2000$ $-4^{\circ}$ Substitutivo, em tramitação na Câmara Federal (Comissão de Desenvolvimento Urbano - CDU). O projeto compreende e integra a dimensão urbanística/ambiental com a jurídica, para que a regularização seja um conjunto de ações para tornar o "habitat" sustentável. A ideia é mais abrangente e promissora nessa proposição legal, convertendo o ciclo vicioso de produção da cidade e irregularidade urbana, em um ciclo virtuoso da regularidade e da cidade legal.

\section{Desenvolvimento}

\subsection{A agricultura urbana e o zoneamento permacultural}

A expansão urbana interfere profundamente na produção e no consumo de alimentos, de forma que a agricultura urbana pode ser vista como uma ferramenta para alcançar a autossuficiência e inibir a deficiência alimentar nas cidades. A escala produtiva da agricultura urbana ainda é subestimada: dados têm demonstrado que o envolvimento de 200 milhões moradores urbanos são capazes de fornecer alimentos para 800 milhões de pessoas (ARMAR-KLEMESU, 2000 apud EMBRAPA, 2002).

A agricultura urbana valoriza o conhecimento local para a promoção da igualdade e utiliza processos participativos e tecnologias a fim de promover gestão urbana, social e ambiental. O escopo global da agricultura urbana promove uma cidade produtiva e ecológica para a segurança alimentar e nutricional de sua população.

Como atividade, a agricultura urbana abrange agro-extração, produção, colheita, transformação e serviço que prevê a produção agrícola e pecuária. As estratégias são direcionadas para consumo próprio, troca, doações e comercialização, de uma forma eficiente e sustentável utilizando recursos locais.

O contexto da agricultura urbana é aplicado em espaços intraurbanos e periurbanos devido às dinâmicas local e regional para que o território e a gestão ambiental da cidade sejam articulados (BRASIL, 2007). É possível programar agricultura urbana em ambos os espaços públicos e privados, sejam eles utilizados para o lazer, cultura, saúde ou economia.

O planejamento urbano por meio dos princípios da agricultura urbana acontece em diferentes níveis do contexto espacial da cidade. Determinar o zoneamento urbano é um processo que deve consolidar as áreas intraurbana, periurbana e rurais em um único ecossistema urbano. A integração destes espaços complementa o espaço rural com o autoabastecimento, os fluxos comerciais e de abastecimento do mercado.

Antes de analisar a questão da legislação urbana no que diz respeito ao zoneamento é importante ter um entendimento do que seria uma integração ideal entre a zona urbana e zona rural, como o que é fornecido pela permacultura. 
Criada pelos australianos Bill Mollison e David Holmgren nos anos 1970, com a fusão de dois conceitos - agricultura e permanente, a permacultura é uma metodologia para o desenho integrado, que tem por finalidade projetar comunidades humanas que funcionem em harmonia com os ecossistemas, baseada na renovação cíclica ao invés da exploração linear.

De acordo com Rodrigues (2000), há quatro estratégias importantes na permacultura: a setorização, o zoneamento, as conexões e as posições relativas dos elementos.

O "zoneamento" é uma estratégia para tomada de decisões em função das necessidades de deslocamentos entre edificação (casa ou edifício) e os elementos a serem projetados na área. Tem como objetivo minimizar o consumo de energia e de trabalho de acordo com as demandas de deslocamento entre edifícios e os outros elementos.

A fim de cumprir as necessidades diárias, a maioria dos elementos - aqueles que recebem mais atenção frequente - são colocados perto dos edifícios; nas zonas restantes estão os elementos que necessitam de áreas de atenção e de preservação menor.

A Figura 2 e a Tabela 1 ilustram o modelo de composição de acordo como o zoneamento proveniente da permacultura, e a funcionalidade de cada zona no contexto local e global do espaço.

A agricultura urbana para o zoneamento urbano, neste caso, não trata apenas de questões de alimento e plantio. Torna-se concreta por meio da contemplação adequada de todos os aspectos relacionados à gestão ambiental e da biodiversidade como uma parte integral do desenho urbano.

Figura 2: Esquema do zoneamento permacultural do espaço.

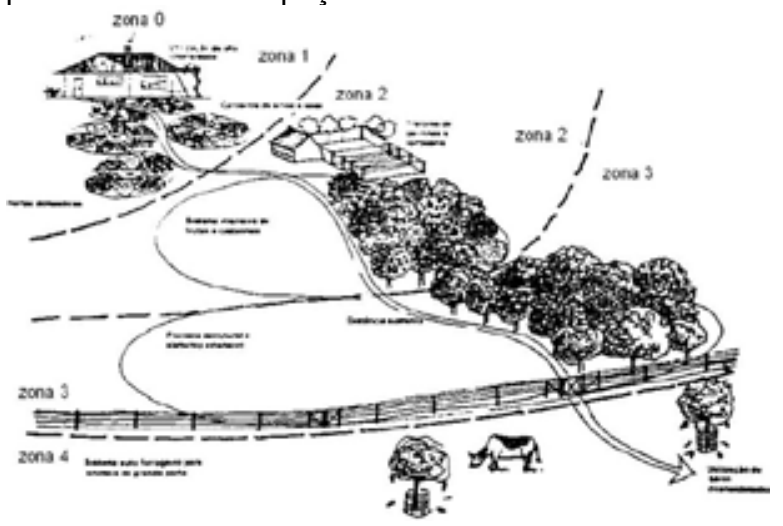

Fonte: Adaptado de Mollison (1998).
É importante ter um conhecimento do local (relevo, recurso hídricos, solo, vegetação, nutrientes etc.), para se consumir o mínimo necessário de energia e trabalho. Nesse sentido, o zoneamento aqui é diferente do zoneamento urbano, que não inclui as características da escala local.

\subsection{A agricultura urbana e zoneamento urbano}

Milton Santos (SANTOS, 1994; SANTOS, 1988; apud BIAZZO, 2008) argumenta que as definições de espaço rural e espaço urbano resultam de características de uso do território, podendo ser urbano com traços de sociabilidades rurais. As características urbanas e rurais são combinadas entre si em cada recorte espacial, seja ele local, micro ou macro. São criados recursos mistos que geram novas territorialidades e tornam possível para um lugar ou uma região abranger ambas as características.

Figura 3: Zonas de agricultura urbana para o zoneamento de uso do solo.

\begin{tabular}{|c|c|}
\hline $\begin{array}{l}\text { ZONA INTRAURBANA } \\
\text { Engloba os critérios de } \\
\text { densidade populacional e os } \\
\text { limiares oficiais da poligonal } \\
\text { urbana da cidade, } \\
\text { abrangendo os espaços que } \\
\text { estão ao alcance das } \\
\text { autoridades legais de } \\
\text { regulamentação do uso do } \\
\text { solo. Inclui aqueles inseridos } \\
\text { dentro ou na periferia da } \\
\text { cidade, usando recursos } \\
\text { Innsic No nrńnris nidsto }\end{array}$ & 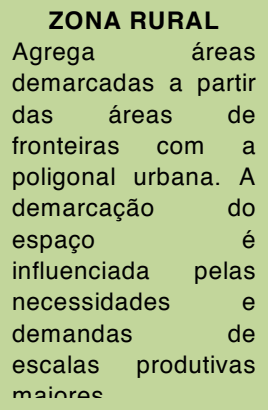 \\
\hline & \\
\hline \multicolumn{2}{|c|}{$\begin{array}{l}\text { Abrange os espaços locados na fronteira do território } \\
\text { urbano com o rural e sofre de maneira significativa todas } \\
\text { as influências que acontecem principalmente do âmbito } \\
\text { rural, mas intensa que aquelas do centro e outras áreas da } \\
\text { cidade. Os limites do espaço variam e dependem das } \\
\text { influências urbanas sobre impactos que podem ocorrer no } \\
\text { sistema produtivo em consideracão. }\end{array}$} \\
\hline
\end{tabular}

Fonte: adaptado de Lemos (2012; p.39)

A prática da agricultura urbana abrange o local como uma referência para a determinação de espaços intraurbano e periurbano, definições que já foram adotadas pelo PNUD e FAO, agências da ONU. Os conceitos aplicam-se na utilização de superfícies pequenas situadas no interior da cidade ou na sua periferia, e sua produção agrícola e criação de pequenos animais são destinadas a consumo próprio ou a mercados locais (SPOTIGHT, 1999; IN EMBRAPA, 2002). 
Tabela 1: Zoneamento permacultural.

\begin{tabular}{|c|c|}
\hline \multicolumn{2}{|r|}{ ZONEAMENTO PERMACULTURAL } \\
\hline Zona permacultural & Descrição \\
\hline zona 0 & $\begin{array}{l}\text { Consiste no centro de atividades, podendo abrigar a casa, o galpão ou a vila urbana; para } \\
\text { essa zona o planejamento é elaborado para que se conserve energia, ajustando-a às } \\
\text { necessidades dos usuários (ocupantes do espaço). }\end{array}$ \\
\hline zona 1 & $\begin{array}{l}\text { É a zona mais próxima à casa ou à vila; aqui há uma maior necessidade de controle, sendo } \\
\text { a zona com maior intensidade de uso. Os conteúdos presentes são: jardim, oficinas } \\
\text { estufas, viveiros de propagação, pequenos animais (galinhas, coelhos, porco da índia, } \\
\text { outros), combustíveis para a casa (lenha e gás), mulch, varal de roupas e a área de } \\
\text { secagem dos grãos. }\end{array}$ \\
\hline zona 2 & $\begin{array}{l}\text { É nesse local que se faz o plantio mais denso de arbustos maiores, pomares mistos e de } \\
\text { frutas menores, quebra-ventos, terraços, sebes, grades e tanques. Algumas espécies de } \\
\text { animais são permitidas (galinhas, patos e outras, desde que domésticas), tomando } \\
\text { cuidado para que fiquem em áreas selecionadas. Também é permitida a criação de vacas } \\
\text { leiteiras, desde que o local seja próximo à zona } 3.0 \text { uso da água é promovido por } \\
\text { irrigação reticulada (gotejamento para árvores). }\end{array}$ \\
\hline zona 3 & $\begin{array}{l}\text { A zona agrupa pomares que não requerem podas e mulch, pastagens maiores para } \\
\text { animais de abate, plantaçőes de maior importância e plantas para forragem animal. A } \\
\text { água fica disponível para algumas plantas, mesmo havendo bebedouros para animais. }\end{array}$ \\
\hline zona 4 & $\begin{array}{l}\text { É uma zona semimanejada e semisselvagem, utilizada para coleta de alimentos mais } \\
\text { resistentes; abriga árvores não podadas e manejo de vida selvagem e floresta. }\end{array}$ \\
\hline zona 5 & $\begin{array}{l}\text { Congrega os sistemas não manejados, ou seja, selvagens. É uma zona de aprendizado e } \\
\text { observação, aqui o usuário se torna visitante e não gerenciador do espaço. }\end{array}$ \\
\hline $\begin{array}{l}\text { Observação: os padr } \\
\text { exemplo, entre a ca } \\
\text { preciso um cuidado }\end{array}$ & $\begin{array}{l}\text { odem mudar se a composição do espaço envolver dois ou mais centros de atividades, por } \\
\text { casa de hóspedes ou, em escala maior, entre as edificações de uma vila. Nesse caso é } \\
\text { na organização dos elos (acessos, suprimentos de energia, água e esgoto, cercas etc.). }\end{array}$ \\
\hline
\end{tabular}

O estabelecimento de fronteiras entre urbano (intraurbano), periurbano e rural envolve vários contextos, para os quais esta pesquisa adota a construção de significados e termos definidos por Mougeot (2000).

O modelo intraurbano do uso do solo acontece dentro dos limites poligonais oficiais da estrutura urbana, associados a critérios de densidade populacional e alcance das autoridades legais e regulamentares. Moustier (apud MOUGEOT, 2000) também discute o uso de tais limites, acrescentando que este modelo faz uso de recursos locais da cidade, enquanto o periurbano usa aqueles que estão fora desse limite. De acordo Mbiba (apud MOUGEOT, 2000), o uso do espaço de outros usos urbanos é considerado para a criação de um modelo deste tipo, tendo em conta o seu potencial de produtividade de alimentação.

Para o modelo periurbano, o uso do solo se concentra na espacialidade da fronteira entre o urbano e o rural, destacando-se que esse espaço recebe influência dramática da zona rural. Mougeot (2000) o define como espaços para os quais o zoneamento não está claramente definido (urbano ou rural). Stevenson (1996, apud MOUGEOT, 2000), por sua vez, afirma que os limites desse modelo variam e dependem das influências urbanas sobre o modo produtivo considerado.

Swindell (apud BINNS \& LYNCH 1998, in MOUGEOT, 2000) afirma que todas as vantagens do urbano e do rural podem ser maximizadas na espacialidade periurbana. Moustier (apud MOUGEOT 2000) destaca certo deslocamento diário máximo entre o núcleo urbano e as fazendas periurbanas, especialmente para o transporte de alimentos perecíveis.

Em termos de deslocamentos, Stevenson (1996, apud MOUGEOT, 2000) também destaca o comércio de produtos nas fazendas. Para que esse comércio ocorra, é importante avaliar o quanto distanciar a cidade do espaço periurbano, uma vez que há uma dependência nas ruas de acesso. Para Ali \& Porciúncula (1999, apud MOUGEOT, 2000) e de acordo com a experiência africana da FAO/ONU, o ideal são os deslocamentos de até $90 \mathrm{~km}$, contados a partir da área poligonal urbana.

As contribuições da agricultura urbana para conduzir o uso do solo se destacam em termos de bem-estar, meio ambiente e economia. Em termos de bem- 
estar, permite a) um aumento da comida provendo segurança alimentar, b) melhorar a saúde humana em comunidades pobres e $c$ ) a redução do surto de doenças. As contribuições para o meio ambiente implicam a conservação dos recursos naturais, menores impactos devido aos assentamentos humanos e ações para a sustentabilidade. Em termos de economia, contribui para a geração de emprego, a redução da pobreza e a promoção do espírito empresarial.

\subsection{Desafios do planejamento urbano no Brasil associados à prática da agricultura urbana e permacultura.}

Para o planejamento urbano, especialmente em termos de zoneamento, grande relevância é colocada em zonas de transição entre os espaços urbanos e rurais. Um exemplo claro são as áreas verdes multifuncionais conjuntas presentes em modelos de redes urbanas, que possibilitam sustentabilidade ao longo de grandes períodos de tempo.

No Brasil, o desenvolvimento da agricultura urbana está intimamente ligada às ações do Ministério do Desenvolvimento Social e Combate à Fome (MDS) que tem implantado ações para a criação de hortas nas escolas, quintais e centros comunitários. $\mathrm{O}$ MDS elaborou um documento de levantamento das principais questões que implicavam a prática da agricultura urbana no Brasil. Como o principal objetivo de sua implantação é o combate à fome, não há interação deles com o Estatuto da Cidade (Lei 10.257/2001), o principal instrumento das políticas urbanas brasileiras do Ministério das Cidades.

A falta de interconexão leva a resultados menos satisfatórios no contexto urbano regional, uma vez que o Estatuto da Cidade consiste num corpo de normas que visam interesses sociais e ordem pública e determina o uso da propriedade urbana para o desenvolvimento da função social das cidades.

A análise dos marcos legais na relação entre a agricultura urbana e planejamento urbano no Brasil (2007), como será ilustrada no próximo item, demonstra a ausência de suporte para a agricultura urbana como uma atividade legal. Isto é verdade não apenas no Brasil, mas em vários países com experiências de agricultura urbana (MOUGEOT, 2005). Independentemente da estratégia adotada, tanto nas esferas nacionais, regionais ou locais, são necessários para a prática a elaboração de modelos objetivos, a fim de alcançar resultados concretos de agricultura urbana em cadeias produtivas local e regional, do consumo e comércio, bem como a partir da técnica e capacidade de gestão.

É necessário superar a precária compreensão e insegurança das ações governamentais contínuos, que são restritas a critérios de ambições políticas de grupos cujas ações são limitadas pelo líder do lugar a qualquer momento. Em termos de promoção da agricultura urbana por meio de políticas urbanas, existem diferentes necessidades e focos. Duas questões que merecem atenção especial estão listadas na Tabela 2.

Estes desafios originam a reflexão sobre o conceito de cidade em face da função social da propriedade estabelecidas e outorgadas pelo Estatuto da Cidade. Inexistem respostas focadas na valorização e reconhecimento do papel da agricultura urbana, a fim de avançar no sentido de uma cidade plural e inclusiva, livre de injustiças socioambientais e marcada pela igualdade em vários sentidos.

Tabela 2: Desafios para a promoção de políticas urbanas voltadas para agricultura urbana.

\begin{tabular}{|c|c|}
\hline \multicolumn{2}{|c|}{$\begin{array}{c}\text { Desafios para a promoção de políticas urbanas } \\
\text { voltadas para agricultura urbana }\end{array}$} \\
\hline Foco & Necessidades \\
\hline 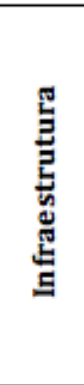 & $\begin{array}{l}\text { Programas públicos para melhorias na } \\
\text { distribuição, armazenagem, distribuição, } \\
\text { processamento, e logística: pontos de } \\
\text { comércio, estocagem, identificação de } \\
\text { produto oriundo da agricultura urbana, } \\
\text { transporte, simplicidade nos procedimentos } \\
\text { de fiscalização sanitária, redução dos custos } \\
\text { de certificação. Tudo isso com foco na } \\
\text { produção de qualidade ambiental, social e } \\
\text { economicamente viável e comprovada. }\end{array}$ \\
\hline 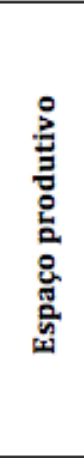 & $\begin{array}{l}\text { Fortalecimento do papel da agricultura } \\
\text { urbana para serviços ambientais, priorizando } \\
\text { a reciclagem e reuso dos recursos naturais } \\
\text { existentes no local. Articular políticas } \\
\text { ambientais, de promoção da saúde e políticas } \\
\text { urbanas às atividades de agricultura urbana } \\
\text { em áreas consideradas de risco e } \\
\text { marginalizadas. Disponibilizar e possibilitar } \\
\text { acessos aos espaços urbanos com potencial } \\
\text { produtivo, identificando-os e caracterizando- } \\
\text { os no plano diretor do município de acordo } \\
\text { com as zonas intraurbana, periurbana e rural. }\end{array}$ \\
\hline
\end{tabular}

Fonte: Brasil (2007); adaptado de Lemos (2012; p. 56). 


\subsubsection{Zoneamento urbano e agricultura urbana - a integração entre o zoneamento permacultural e zoneamento da agricultura urbana}

A pesquisa sobre agricultura urbana nas cidades e o zoneamento urbano apresentado no artigo demonstra possibilidades concretas de elaboração de um zoneamento urbano integrado para atividades da agricultura urbana. A Tabela 3 explicita a integração entre o zoneamento permacultural e a agricultura urbana, conduzindo a criação de um zoneamento urbano que contemple a agricultura urbana.

No zoneamento proposto aqui, a produtividade e a configuração espacial são integrados por princípios ecológicos e experiências de vida urbanas locais, além de interligar regiões urbanas que não são interdependentes.
Pode-se ver uma clara definição das zonas, uma vez que estas são estabelecidas como intraurbana, periurbana e rural; permitindo a definição exata do espaço que hoje limita a região para o que é urbano e o que é rural.

As técnicas implantadas pelo zoneamento urbano integrado à agricultura urbana implica a utilização dos mesmos princípios éticos para cada espaço. Entretanto, as particularidades locais conduzirão às diferentes estratégias e técnicas, uma vez que não existem dois ambientes iguais.

Este modelo apresenta uma visão holística integrada de configuração espacial, na qual a arquitetura e o urbanismo são combinados para biologia, arquitetura, engenharia florestal e zootecnia, entre outros. É necessário que essa visão seja refletida nas políticas públicas e legislações em relação

Tabela 3: Síntese do zoneamento urbano com agricultura urbana.

Zoneamento urbano com a agricultura urbana: desenho de uso do solo com a agricultura urbana

\begin{tabular}{|c|c|c|c|c|}
\hline \multirow{2}{*}{$\begin{array}{l}\text { Zoneamentos } \\
\text { integrados }\end{array}$} & \multicolumn{3}{|c|}{$\begin{array}{c}\text { Zoneamento para agricultura } \\
\text { urbana }\end{array}$} & \multirow[t]{2}{*}{ Descrição } \\
\hline & Intraurbana & Periurbana & Rural & \\
\hline \multirow{7}{*}{$\begin{array}{l}\text { Zoneamento } \\
\text { permacultural }\end{array}$} & Zona 0 & & Zona 0 & $\begin{array}{l}\text { Atividades centralizadas no espaço interno da casa, do } \\
\text { edifício, do galpão e da vila. }\end{array}$ \\
\hline & Zona 1 & & Zona 1 & $\begin{array}{l}\text { Atividades produtivas nas proximidades imediatas da } \\
\text { casa, galpão ou vila. Produção em jardins residenciais, em } \\
\text { espaços entre as casas ou edifícios, em paredes de casas } \\
\text { ou edifícios, em telhados ou lajes (telhado verde). }\end{array}$ \\
\hline & Zona 2 & & Zona 2 & $\begin{array}{l}\text { Atividades produtivas nas proximidades da casa, galpão } \\
\text { ou vila. Produção em canteiros centrais ou laterais de vias } \\
\text { de circulação dentro da poligonal urbana, em praças e } \\
\text { terrenos baldios, em passarelas de circulação de } \\
\text { pedestres e ciclistas, em margens de cursos d'água e lagos } \\
\text { no interior da poligonal urbana. } \\
\end{array}$ \\
\hline & & Zona 3 & Zona 3 & $\begin{array}{l}\text { Atividades relativamente distantes da casa, do edifício, do } \\
\text { galpão e da vila. Produtividade em padrões de } \\
\text { agrofloresta, aplicadas em laterais de vias de acesso entre } \\
\text { a poligonal urbana e a área rural, margens de cursos } \\
\text { d'água, áreas inundáveis, faixas de alta tensão, e áreas de } \\
\text { tratamento (aterro sanitário e lagoa de oxidação). }\end{array}$ \\
\hline & & Zona 4 & Zona 4 & $\begin{array}{l}\text { Atividades distantes da casa, do edifício, do galpão e da } \\
\text { vila. Produtividade em margens de cursos d'água, áreas } \\
\text { inundáveis, e unidades com uso permitido para manejo } \\
\text { de potencialidades. }\end{array}$ \\
\hline & & & Zona 5 & $\begin{array}{l}\text { Atividades bem distantes da casa, do edifício, do galpão e } \\
\text { da vila. Produtividade baixa, pois é área de transição } \\
\text { integrada por sistemas selvagens, em que não há um } \\
\text { gerenciador do espaço. }\end{array}$ \\
\hline & \multicolumn{4}{|c|}{$\begin{array}{l}\text { Observações: para o espaço rural, todas as zonas do zoneamento permacultural podem existir no } \\
\text { espaço, pois estas suprirão as necessidades da fazenda a partir da casa. Apenas uma delas será } \\
\text { enfatizada e intensificada, de modo que esta consiga atender o mercado local de maneira coerente } \\
\text { com o proposto pela fazenda. A zona rural em resumo consolida a aplicação do zoneamento } \\
\text { permacultural tradicional. }\end{array}$} \\
\hline
\end{tabular}

Fonte: adaptado de Lemos et. al (2013). 
às questões urbanas, sociais e econômicos, em diálogo aberto com os contextos ambientais. Tais combinações deveriam ser contempladas nos planos diretores que governam as diretrizes e o uso e ocupação do solo como um todo.

\subsubsection{Aplicação do zoneamento urbano integrado com a agricultura urbana para enquadramento legal da política urbana no Brasil}

A análise do Estatuto da Cidade revela a ausência de qualquer menção à agricultura urbana na zona urbana. Em suas disposições gerais (Capítulo II, Art. $4^{\circ}$, da Lei $10.257 / 2001$ ), a necessidade de fazer urbana agricultura como parte do plano diretor da cidade e do território, associada ao uso do solo nos planos municipais, não é explícita. A considerar esta primeira leitura, e alinhado ao objetivo da presente pesquisa, considerou-se mais pertinente para análise os capítulos II e III da mesma lei, e também nos capítulos II, III e V da Lei 6.766/1979.

Em Lemos (2012, p. 52 a 61) há um estudo detalhado a respeito dos capítulos supracitados, mostrando a lacunas de cada um deles, e como a agricultura urbana pode ser inserida em cada capítulo. Verificou-se que os instrumentos de planejamento urbano do uso e ocupação do solo ainda são muito conservadores no que tange à sustentabilidade urbana e sua visão sistêmica, em relação à cidade-campo (ANDRADE, 2009).

Tabela 4: Síntese da análise da política urbana brasileira.

\begin{tabular}{|c|c|c|}
\hline \multicolumn{3}{|c|}{ Síntese da análise da política urbana brasileira } \\
\hline $\begin{array}{c}\text { Lei 10.257/2001 - Estatuto da } \\
\text { Cidade }\end{array}$ & Sugestão de inclusão & Diretrizes para agricultura urbana \\
\hline $\begin{array}{l}\text { Capítulo II - dos instrumentos da } \\
\text { política urbana, art } 4^{\circ}\end{array}$ & $\begin{array}{c}\text { abertura para inclusão de dois } \\
\text { novos incisos }\end{array}$ & $\begin{array}{l}\text { Abordar a agricultura urbana - AU como } \\
\text { prática inserida ao planejamento municipal } \\
\text { (em caráter especial). } \\
\text { Determinar a elaboração de um zoneamento } \\
\text { agrícola urbano. }\end{array}$ \\
\hline $\begin{array}{l}\text { Capítulo II - dos instrumentos da } \\
\text { política urbana, art } 42\end{array}$ & $\begin{array}{l}\text { abertura para uma } \\
\text { complementação }\end{array}$ & $\begin{array}{l}\text { Delimitar áreas urbanas com potencial para } \\
\text { produção de alimentos: especificar o uso de } \\
\text { espaços disponíveis ou não edificáveis com } \\
\text { potencial para AU por meio de definição de } \\
\text { Zonas Especiais de Interesse Social. }\end{array}$ \\
\hline $\begin{array}{c}\text { Lei } 6.766 / 1979 \text { - dispõe sobre o } \\
\text { parcelamento do solo urbano e } \\
\text { dá outras providências }\end{array}$ & Sugestão de inclusão & Diretrizes para agricultura urbana \\
\hline $\begin{array}{l}\text { Capítulo II }- \text { dos requisitos } \\
\text { urbanísticos para loteamento, art } \\
4^{\circ}\end{array}$ & $\begin{array}{l}\text { abertura para um novo inciso } \\
\text { (em comparação ao inciso II) e } \\
\text { para um novo dispositivo }\end{array}$ & $\begin{array}{l}\text { Abordar área dos lotes destinados a } \mathrm{AU} \\
\text { intraurbana. } \\
\text { Mencionar os lugares que poderão praticar } \mathrm{AU} \text {. }\end{array}$ \\
\hline $\begin{array}{l}\text { Capítulo II }- \text { dos requisitos } \\
\text { urbanísticos para loteamento, art } \\
4^{\circ} \text {, inciso IV, } \S 2\end{array}$ & $\begin{array}{l}\text { abertura para uma } \\
\text { complementação }\end{array}$ & 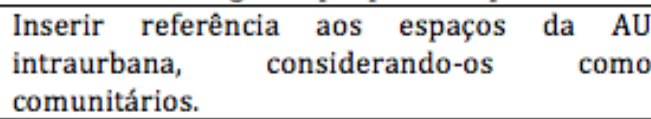 \\
\hline $\begin{array}{l}\text { Capítulo II }- \text { dos requisitos } \\
\text { urbanísticos para loteamento, art } \\
5^{\circ}\end{array}$ & $\begin{array}{l}\text { abertura para uma } \\
\text { complementação }\end{array}$ & $\begin{array}{l}\text { Introduzir que a esfera pública competente } \\
\text { também terá autonomia para exigir ou não a } \\
\text { reserva de área ao fundo dos lotes para } \mathrm{AU} \text {. }\end{array}$ \\
\hline $\begin{array}{l}\text { Capítulo III - do projeto de } \\
\text { loteamento, art } 6^{\circ}\end{array}$ & abertura para um novo inciso & $\begin{array}{l}\text { Exigir a publicidade da localização das áreas } \\
\text { da AU para o estudo de propostas de } \\
\text { loteamento. }\end{array}$ \\
\hline $\begin{array}{l}\text { Capítulo III }- \text { do projeto de } \\
\text { loteamento, art } 7^{\circ}\end{array}$ & $\begin{array}{c}\text { abertura para uma } \\
\text { complementação no inciso III }\end{array}$ & $\begin{array}{l}\text { Abordar a AU em conjunto para localização de } \\
\text { terrenos destinados para fins específicos. }\end{array}$ \\
\hline $\begin{array}{lcr}\text { Capítulo V - da aprovação do } \\
\text { projeto de loteamento } \\
\text { desmembramento, art 13 }\end{array}$ & $\begin{array}{c}\text { abertura para uma } \\
\text { complementação no inciso III }\end{array}$ & $\begin{array}{l}\text { Abrir exceção para os espaços periurbanos } \\
\text { destinados à prática da } \mathrm{AU} \text {, desde que estejam } \\
\text { determinados no zoneamento de uso do solo. }\end{array}$ \\
\hline $\begin{array}{l}\text { Capítulo V - da aprovação do } \\
\text { projeto de loteamento e } \\
\text { desmembramento, art } 22\end{array}$ & $\begin{array}{l}\text { abertura para uma } \\
\text { complementação }\end{array}$ & $\begin{array}{l}\text { Introduzir áreas com destinação para AU em } \\
\text { propostas de loteamento com o domínio do } \\
\text { município, assim como os demais } \\
\text { mencionados. }\end{array}$ \\
\hline
\end{tabular}

Fonte: adaptado de Lemos (2012, p.60). 
$\mathrm{Na}$ Tabela 4, por exemplo, observa-se o distanciamento das ações e possíveis aplicações das práticas de agricultura urbana no contexto das duas leis de uso e ocupação do solo.

O planejamento urbano, grosso modo, é ainda caracterizado por um modelo de zoneamento polarizado entre urbano e rural, o que subestima a zona intermediária. Assim, torna-se importante a inclusão da agricultura urbana nas políticas urbanas brasileiras, não apenas pela atividade em si, mas também para a aplicação da sustentabilidade urbana, tendo em vista o planejamento de zoneamento que divide as áreas em zonas urbana, periurbana e rural.

Ao longo deste estudo, tornou-se claro que as leis para as políticas urbanas brasileiras não introduzem a prática da agricultura urbana no zoneamento urbano. É necessário ainda avançar, levando-se em consideração essas relações e priorizando aspectos multifuncionais, contando com a participação popular na gestão do espaço, a fim de incentivar projetos integrados.

Os regulamentos das políticas urbanas devem fomentar e possibilitar mudanças nos agenteschave da sociedade, a fim de alcançar os objetivos propostos. No contexto da agricultura urbana, associada às estratégias de desenho urbano, as políticas devem ser entendidas como parte de um longo processo em que marcos legais irão espelhar a prática da atividade. Ao mesmo tempo, permitem promover uma mobilização das pessoas na direção da consciência ambiental como instrumento de educação para a sustentabilidade.

No entanto, é necessário que os objetivos das políticas urbanas estejam em consonância com outras políticas governamentais, de modo que a prática da agricultura urbana possa se tornar um método eficaz de aplicação no zoneamento urbano e legitimar os subsídios da atividade no território urbano.

\section{Agradecimentos}

Agradecemos a $\operatorname{Prof}^{\mathrm{a}} \mathrm{Dr}^{\mathrm{a}}$ Marta Adriana Bustos Romero e organizadores pela oportunidade de publicar o trabalho na Revista Paranoá, em edição especial com tema "Olhares da Reabilitação Ambiental Sustentável".

\section{Conclusão}

A pesquisa demonstra que estabelecer ligações entre o zoneamento urbano e a agricultura urbana permite a criação de comunidades humanas sustentáveis que integram a composição com a ecologia e o território urbano, aplicando conhecimento comum ao urbano e rural. Este tipo de associação faz com que o ambiente da cidade se torne um ecossistema composto por grupos que interagem entre si e com o ambiente físico, coexistindo em um sistema natural mais sustentável e complexo.

A pesquisa na temática da agricultura urbana direcionada ao planejamento urbano ainda requer um maior detalhamento. $\mathrm{O}$ objetivo desta pesquisa consistia em preliminarmente demonstrar os desafios dos marcos legais no contexto brasileiro que ainda estão longe de alcançar uma integração entre o zoneamento urbano e rural, nas zonas urbanas e periurbanas. Exige-se ainda mais atenção, a fim de chegar a uma melhor compreensão do desenho urbano, quando as três principais zonas são aplicadas, seja na escala de um lugar, seja em na escala regional e urbano.

A principal contribuição deste trabalho foi apontar a lacuna existente e chamar a atenção dos planejadores urbanos e técnicos de governo com sugestões de diretrizes para complementar a política urbana brasileira. Entende-se que a incorporação de um zoneamento urbano integrado permitiria à promover a responsabilidade da produção de alimentos e sustentabilidade ambiental nas cidades.

\section{Referências}

ANDRADE, L. M. S. Princípios de Sustentabilidade para Reabilitação Ambiental de Assentamentos Urbanos. Capítulo 6 in ROMERO, M. A. B. (Org.); DRESH, Daniel; RODRIGUES, Joe (colab.). Reabilitação Ambiental Sustentável Arquitetônica e Urbanística. Brasília: FAU/UnB, 2009.

BIAZZO, P. P. Campo e Rural, Cidade e Urbano. In $4^{\circ}$ ENCONTRO NACIONAL DE GRUPOS DE PESQUISA - ENGRUP. São Paulo, 2008.

BRASIL. Ministério do Desenvolvimento Social e Combate à Fome. Panorama da agricultura urbana e periurbana no Brasil e diretrizes políticas para sua promoção. Belo Horizonte, 2007. 
EMBRAPA. Documentos 48: Agricultura Urbana. Planaltina, 2002.

LEMOS, N. S. Marcos legais e agricultura urbana no contexto da cidade sustentável. Monografia (Especialização) - FAU/UnB, Brasília, 2012.

LEMOS, N. S. ANDRADE, L. M. S.; MEDEIROS, V. A. S. Urban planning through the prism of urban agriculture In: INTERNATIONAL CONFERENCE ON CHANGING CITIES: SPATIAL, MORPHOLOGICAL, FORMAL \& SOCIO-ECONOMIC DIMENSIONS. 2013,

MOLLISON, Bill; SLAY, R. M. Introdução à Permacultura. Tradução: André Luis Jaeger Soares. Brasília: MA/ SDR/ PNFC, 1998.

MOUGEOT, Luc J. A. Urban agriculture: definition, presence, potentials and risks. In: BAKKER, N.; DUBBELING, M.; GÜNDEL, S.; SABELKOSCHELLA, U.; ZEEUW, H. (Ed.). Growing cities, growing food. Feldafing: Deutsche Sitffung für Internationale Entwicklung, 2000.

MOUGEOT, Luc J. A. Agropolis - The Social, Political and Environmental Dimensions of Urban Agriculture. Earthscan and the International Development Research Centre (IDRC). UK, USA e Canadá: 2005.

MOORE, P. D. Agricultural and Urban Areas. Chelsea House. Nova lorque: 2006.

RODRIGUES, M. A. P. Potencialidades da permacultura na arquitetura da paisagem no Cerrado. Dissertação (Mestrado) - FAU/UnB, Brasília, 2000. 


\section{Eixo 03}

\section{O estudo da sustentabilidade, da revisão da legislação urbana ou patrimonial e do planejamento urbano como ferramentas de um futuro melhor para as cidades}

73 Palácio Itamaraty em Brasília: análise de adequação às normas brasileiras sobre acessibilidade e propostas de melhoria, respeitando a autenticidade MÁXIMO, Marco Aurélio da Silva; FERREIRA, Oscar Luís

83 O Estudo de impacto de vizinhança (EIV) como estratégia de requalificação urbana. $O$ caso do Distrito Federal

MARQUES, Alessandra Leite; SILVA, Caio Frederico e

95 Estratégias locais para tornar as cidades mais resilientes: o caso de Garibaldi (RS)

MANFREDINI, Constance; SATTLER, Miguel Aloysio

105 Sustentabilidade, planejamento urbano e instrumentos de gestão do patrimônio e da paisagem cultural em Bento Gonçalves/RS

BERTOCO, Cristiane; MEDEIROS, Ana Elisabete 
